Research Article

\title{
Numerical Investigation on Time-Dependent Deformation in Roadway
}

\author{
Yuantian Sun $\mathbb{D D}^{1}{ }^{1}$ Guichen Li $\mathbb{D}^{1},{ }^{\mathrm{J}}$ unfei Zhang, ${ }^{2}$ Bicheng Yao, ${ }^{1}$ Deyu Qian, \\ and Jiandong Huang ${ }^{1}$ \\ ${ }^{1}$ Key Laboratory of Deep Coal Resource Mining, Ministry of Education of China, School of Mines, \\ China University of Mining and Technology, Xuzhou 221116, China \\ ${ }^{2}$ School of Civil and Transportation Engineering, Hebei University of Technology, 5340 Xiping Road, Beichen District, \\ Tianjin 300401, China
}

Correspondence should be addressed to Guichen Li; liguichen@cumt.edu.cn

Received 30 October 2019; Revised 17 February 2021; Accepted 14 March 2021; Published 10 April 2021

Academic Editor: Fan Gu

Copyright $\odot 2021$ Yuantian Sun et al. This is an open access article distributed under the Creative Commons Attribution License, which permits unrestricted use, distribution, and reproduction in any medium, provided the original work is properly cited.

\begin{abstract}
The roadway deformation normally relates to time especially for underground coal roadway. The strength of soft coal is low, and therefore the deformation increases gradually under constant stress with time, which is called rheology deformation. In this study, based on a field case, the rock mass properties and deformation data of the roadway were obtained according to the field test. A 3D numerical model was then established, and the rheological deformation including horizontal and vertical deformation of the coal roadway was systematically analyzed. The results showed that the rheological deformation of horizontal sidewall accounts for almost $30 \%$ of the whole deformation, and the stable time for such roadway is around 60 days after excavation. The tendency of the roof deformation is similar to the sidewalls, and however, the floor deformation is different. Then the related suggestions for maintaining the stability of such roadway were proposed, which is useful in-field application.
\end{abstract}

\section{Introduction}

Driving tunnels in deep conditions especially in the underground coal mine is a challenge [1]. There are a lot of roadways with soft coal mass in coal mines in China, which normally occurs with large deformation and failure [2]. Parts of the roadways are in soft geological conditions such as coal roadway and weak rock mass, and therefore, the deformation exhibited time-dependent behaviors [3-5]. Also, to maintain the stability of such roadway, a series of approaches have been proposed such as high-stress support, grouting reinforcement, and a combination support system. However, most of the methods are based on experience [6]. To understand the mechanism of rheological deformation of coal roadway and its optimum support system, numerical modeling could be a good choice [7-10].

Due to the high efficiency of numerical simulation, more scholars used numerical modeling to deal with field problems. For instance, there is some commercial software such as FLAC, FLAC3D, UDEC, and 3DEC, which are used in geotechnical engineering or underground engineering [11-14]. By these programs, the stability of the roadway in underground conditions can be simulated and calculated quickly, meaning the decision can be made soon based on numerical results. Moreover, to improve the efficiency and accuracy of numerical modeling, some combined methods have been proposed such as FLAC+UDEC and FLAC3D+RS [15]. However, to address a specific question, the geological condition is also an important factor. For example, the rock mass properties affect the deformation obviously, and thus accurate input parameters can improve the accuracy significantly. Though the above methods have been used and engineering problems have been solved, there are still questions in rheological deformation in the roadway in underground mines [16]. The whole process of time-dependent deformation, i.e., from excavation to failure of the roadway, needs to be investigated systematically. 
This study focuses on the rheological deformation of coal roadway. To reveal the mechanism of this, a numerical model was established by FLAC3D, by which the creep constitutive model (CVISC) was used to simulate the timedependent deformation of the coal roadway. Then the results were discussed, and the relevant suggestions were proposed. The study can be used for guiding field application.

\section{Field Observation}

Guobei coal mine is selected as the study area, which is located in Huaibei, China. The depth of the studied working panel 8204 is over $700 \mathrm{~m}$. Due to the soft coal mass, large deformation and roof collapse normally occur (Figure 1(a)). On the roadway profile, the monitoring points have been set as shown in Figure 1(b). Also, three monitoring stations were set in the roadway for obtaining the deformation constantly (Figure 1(c)). It should be pointed out that due to the large time-dependent deformation, the roof and sidewalls have been recaved several times, and therefore the data are accumulative deformation, and the average value are used from three monitoring stations.

The wall to wall and floor-to-roof convergences have been collected (shown in Figure 2). As can be seen, the maximum convergence of sidewalls and roof-to-floor displacement reached $880 \mathrm{~mm}$ and $310 \mathrm{~mm}$ (Figure 2(a)), respectively. There are two stages (stages A and B) indicating the deformation behavior of the roadway. Stage A depicted that the displacement rate decreased quickly in around 60 days. However, stage B illustrated a rheological deformation gradually (Figure 2(b). As described above, the time-dependent deformation is close to soft coal mass as it is easy in rheology. In the following part, a numerical model is established and the relevant deformation properties are revealed.

\section{Numerical Simulation and Results}

3.1. Model Settings. The software FLAC3D was applied in this study. To simulate the true condition of the roadway, a $3 \mathrm{D}$ model was established (Figure 3 ). The height and the width of the model are both $60 \mathrm{~m}$. The length of the model is $100 \mathrm{~m}$. To obtain a high-accurate result, the monitoring station is set in the middle of the model. The size effect and boundary effect were verified. On the boundary of the model, vertical stress and horizontal stress were applied according to the literature [15]. The bottom of the model was fixed, and the left and right boundaries were set as roller boundaries.

In the field, the conventional support, i.e., rock bolts and shotcrete, was used, and therefore, the shell and cable elements were applied in the $3 \mathrm{D}$ model. It should be pointed out that the U-shaped steel sets were also applied by shell elements. The parameters used in the numerical model are given in Table 1.

As for the rock mass properties, the geological strength index (GSI) was used, and based on the GSI value, the relevant parameters such as cohesion, Young's modulus, and friction angle are therefore obtained. However, normally the
GSI is according to an empirical chart, and some key information is difficult to find. The rock mass rating (RMR) classification system was used based on the following equations [17-19]. Then the rock mass properties of surroundings are summarized in Table 2.

$$
\mathrm{GSI}=\mathrm{RMR}-5 .
$$

This work concerned the rheological behavior of soft coal mass around the roadway. Therefore, the selection of a constitutive model is critical. In FLAC3D, the CVISC model (related to real time) can simulate the time-dependent behavior of materials, and thus in the model, the coal materials are assigned CVISC. The rheological parameters, $\eta^{\mathrm{M}}, G^{M}, \eta^{\mathrm{K}}$, $G^{K}, C, \varphi$, and $E$ represent the basic parameters [20]. Normally, they are difficult to obtain because of the size effect of the sample, which means that the results of rock samples cannot be used in rock mass directly. Thus, a back-analysis approach was used to find the rheological parameters of coal mass [21]. The results are summarized in Table 3. Then based on the numerical calculation results, the mechanism of rheology properties of coal roadway can be revealed.

3.2. Model Validation. The validation of the model is significant. In this part, the numerical model runs, and the results of 300 days were monitored including the sidewalls convergence and deformation rate (Figure 4 ). Ten representative points with their displacement were select from the simulated results (Figure 4(a)), and the deformation rate calculated by the monitoring results is also shown in Figure 4(b). The results showed that the simulation results (sidewalls convergence and deformation rate) are close to field data, meaning that the model is correct and accurate, which can be used for further application.

3.3. Time-Dependent Deformation Analysis. According to the numerical model, the vertical deformation and horizontal deformation were further investigated. The deformation in typical days was chosen (i.e., 3d, 15d, 60d, 150d, and 300d) for analysis and comparison.

For horizontal displacement, it is shown in Figure 5 (only left sidewall). As can be seen, with the increase of time, the displacement of sidewalls increased. Before 60 days, the displacement of sidewalls increases sharply, which means that the coal mass failed quickly and the movement of coal mass in the deep area also deformed. From the figure, the support system failed obviously because of the large extrusion of the sidewalls. After that, the deformation of the sidewall increased gradually, and the reason is that the rheology of coal mass was exhibited in this stage. It can be calculated that the rheological deformation of the sidewall accounts for almost $30 \%$ of the whole deformation. According to the experience, when the convergence of sidewalls reached $600 \mathrm{~mm}$, the roadway should be recaved and maintained, denoting that the stable time for such roadway is around 60 days.

Furthermore, the vertical displacement of the roadway is shown in Figure 6. The tendency of the roof deformation is 


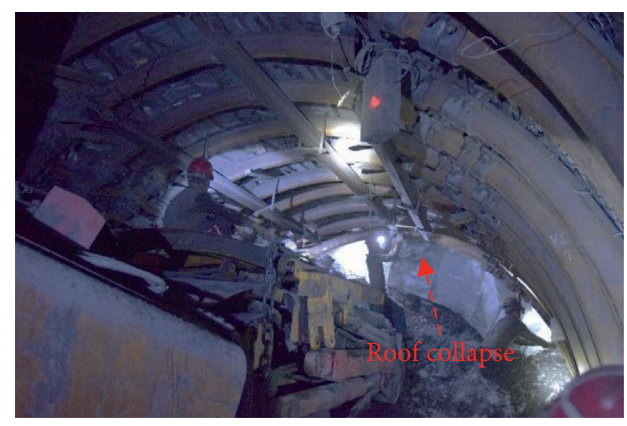

(a)

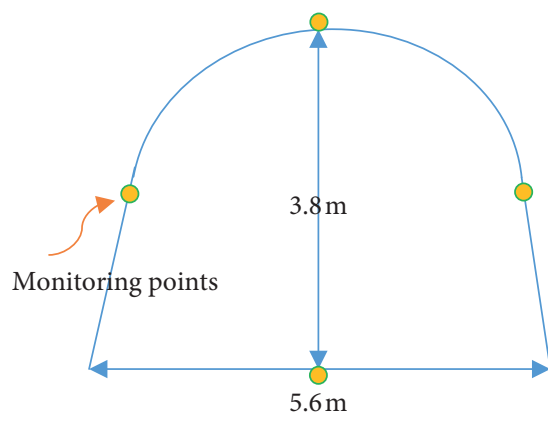

(b)

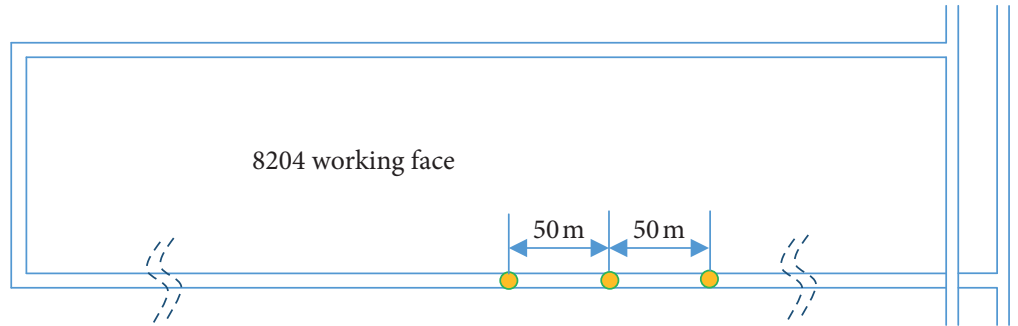

(c)

Figure 1: The studied roadway: (a) the roof collapse in the roadway; (b) the monitoring points on roadway profile; (c) the monitoring stations in the roadway.

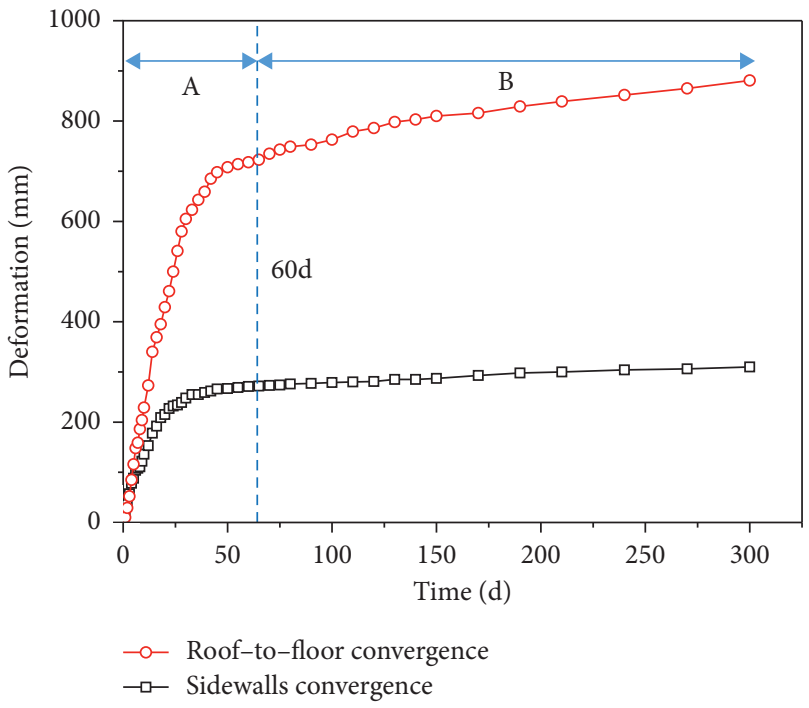

(a)

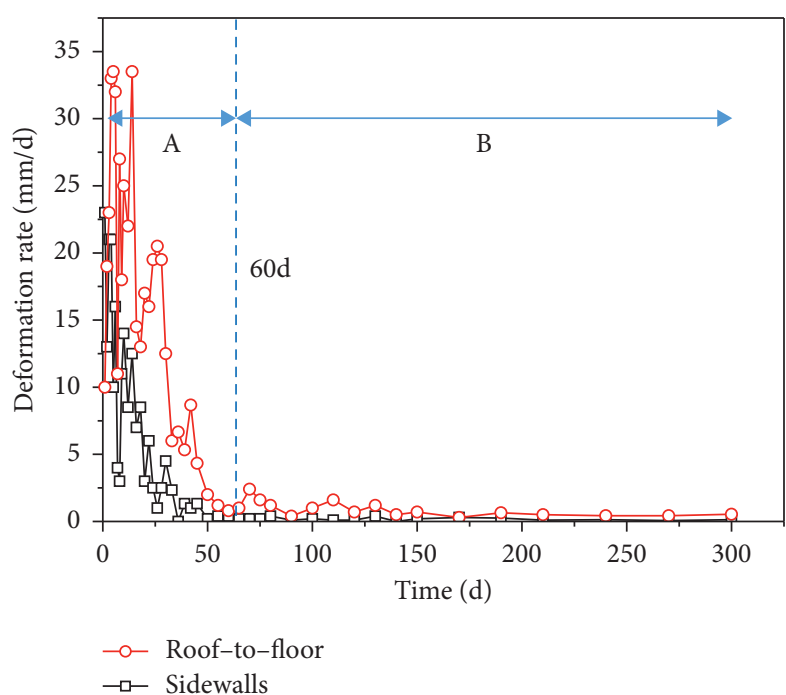

(b)

Figure 2: Measured data of roadway: (a) convergence; (b) deformation rate.

similar to the sidewalls, and however, the floor deformation is different. As can be seen, before 60 days, the deformation of the roof increased sharply with the increase of time. After 60 days, it increased slowly. The reason is that the lithology of the immediate roof is soft coal mass, and therefore the time-dependent behavior of coal can be found obviously, which means that the roof deformation can also exhibit rheological properties. As for the floor, the lithology of that is mudstone, and it normally displayed a plastic failure in a short time. That is why the floor heave keeps constant after
20 days. According to the comparison of the roof deformation and floor deformation, the rheology of soft coal is critical for roadway stability, and a detailed discussion is needed for keeping such roadway stability.

\section{Discussion and Suggestions}

The stability of roadway with soft coal mass is a quite challenging issue in deep underground coal mines. The deformation behavior especially for the time-dependent 


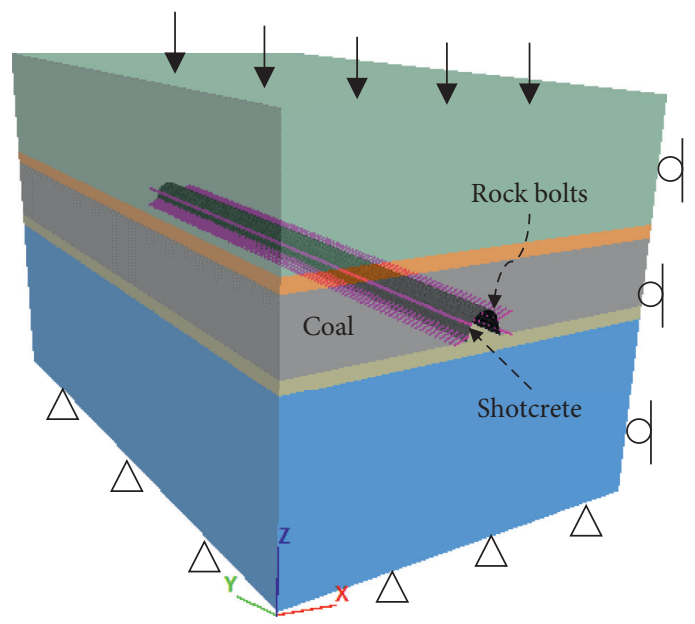

FIgURE 3: 3D numerical model.

TABLE 1: The support materials.

\begin{tabular}{lccc}
\hline Parameters, unit & Rock bolt & U-shaped steel sets & Shotcrete \\
\hline Elastic modulus $(\mathrm{GPa})$ & 200 & 200 & 30 \\
Poisson's ratio & 0.3 & 0.25 & 0.15 \\
Diameter/thickness $(\mathrm{mm})$ & 22 & 15 & 100 \\
\hline
\end{tabular}

TABLE 2: Rock mass properties.

\begin{tabular}{lccccccccccc}
\hline \multirow{2}{*}{ Rock unit } & \multicolumn{4}{c}{ Rock material properties } & \multicolumn{5}{c}{ Rock mass properties } \\
& $m_{\mathrm{i}}$ & Density $\left(\mathrm{kg} / \mathrm{m}^{3}\right)$ & $\sigma_{\mathrm{ci}}(\mathrm{MPa})$ & Poisson's ratio $(v)$ & $E_{\mathrm{i}}(\mathrm{GPa})$ & $\mathrm{RMR}$ & $\mathrm{GSI}$ & $C(\mathrm{MPa})$ & $\phi\left({ }^{\circ}\right)$ & $\sigma_{\mathrm{t}}(\mathrm{MPa})$ & $\mathrm{E}_{\mathrm{mass}}(\mathrm{GPa})$ \\
\hline Sandstone & 9 & 2690 & 85.8 & 0.22 & 18.6 & 72 & 67 & 3.45 & 42 & 0.79 & 12.5 \\
Mudstone & 9 & 2700 & 38.5 & 0.29 & 3.61 & 40 & 35 & 1.24 & 27 & 0.3 & 0.4 \\
Coal & 30 & 1420 & 7.0 & 0.39 & 5.0 & 35 & 30 & 0.98 & 24 & 0.15 & 0.50 \\
Mudstone & 16 & 2710 & 27.8 & 0.25 & 3.1 & 39 & 34 & 1.21 & 26 & 0.3 & 0.25 \\
Sandstone & 8 & 2680 & 62.5 & 0.21 & 12.8 & 65 & 60 & 2.85 & 40 & 0.51 & 8.9 \\
\hline
\end{tabular}

TABLe 3: The rheological parameters of coal mass.

\begin{tabular}{lccc}
\hline$\eta^{\mathrm{M}}(\mathrm{MPa} . \mathrm{d})$ & $G^{M}(\mathrm{MPa})$ & $\eta^{\mathrm{K}}(\mathrm{MPa} . \mathrm{d})$ & $G^{K}(\mathrm{MPa})$ \\
\hline $1.41 \mathrm{e} 5$ & $1.36 \mathrm{e} 2$ & $2.54 \mathrm{e} 7$ & $2.21 \mathrm{e} 2$ \\
\hline
\end{tabular}

deformation is quite serious. For this study of soft coal roadway, the deformation is closely related to the rheology and evolutionary failure of the coal mass. Thus, based on the field measurement and numerical simulation, this study first revealed that the deformation of deep soft coal roadway illustrated the decelerating rheology in about 60 days and uniform rheology in the long-term, causing large roadway convergence in service life (1 to 2 years) compared with stable rock roadway (5 to 10 years) [22-24]. Consequently, the research results from rock roadway could not directly be applied to soft coal roadway. This study revealed the process of deformation deterioration behavior with time.

According to the above discussion, the time-dependent behavior of coal is tightly associated with roadway instability (i.e., large rheological deformation with time). Consequently, improving the strength of coal mass is necessary for roadway stability. Grouting can be used in complex conditions especially for rheological materials such as fragment rock and coal mass, which has been used in some cases successfully [25-28]. Nowadays, the jet grouting technique is also presented and is tried in the field [29, 30], which can totally improve the strength of coal mass by a mechanical process. In the future, it is very promising. Moreover, the delayed grouting can be applied in coal mass, and however, it is difficult to control the grouting time. At present, the grouting cable bolts with pretension are presented, and they are used successfully in some cases [31]. Thus, this approach can be used in such soft conditions as well. 


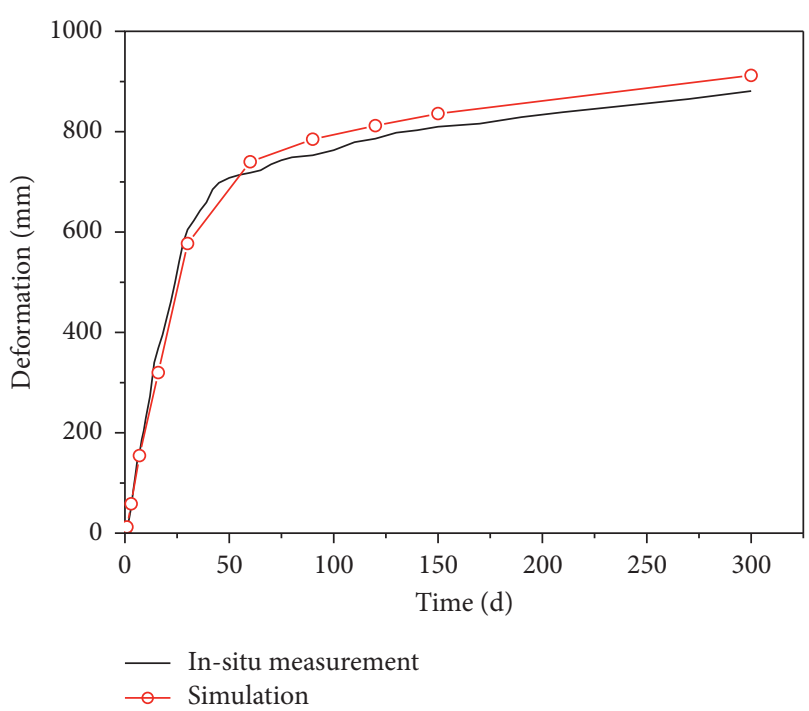

(a)

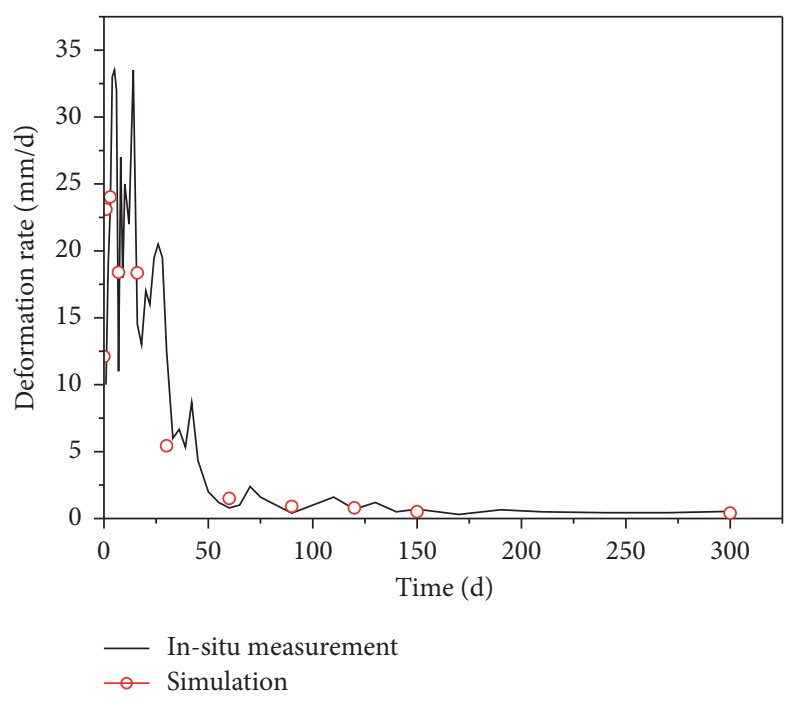

(b)

FIGURE 4: Comparison of results: (a) convergence; (b) deformation rate.

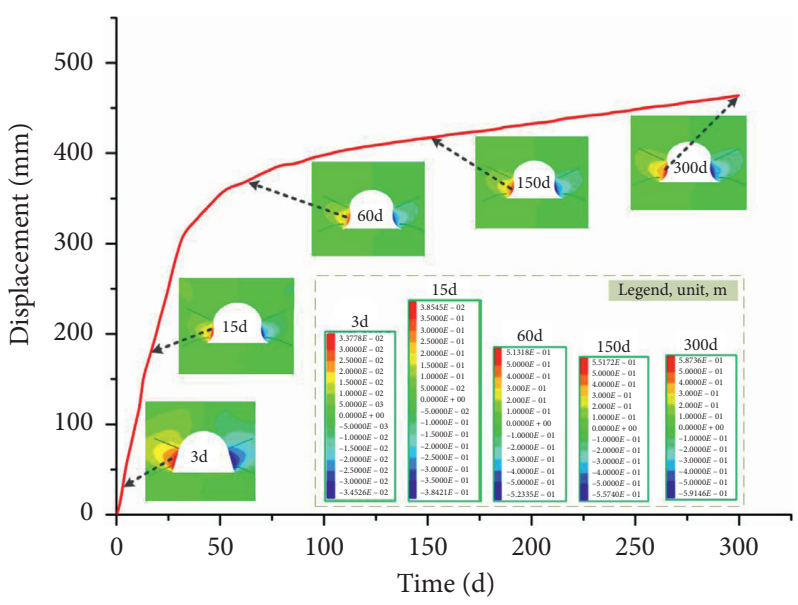

FIgURE 5: The horizontal displacement of roadway.

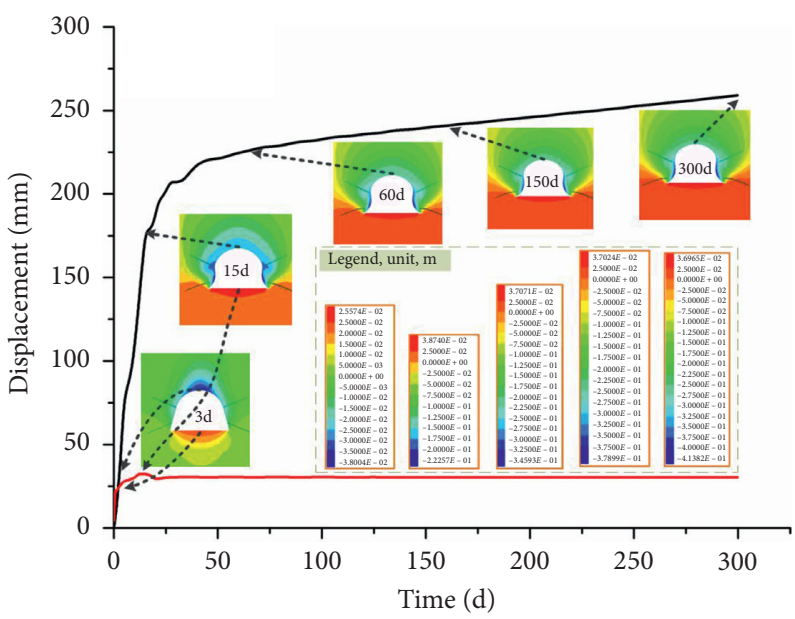

Figure 6: The vertical displacement of roadway. 


\section{Conclusions}

Based on the typical engineering of soft coal roadway, a time-dependent 3D numerical model was established and verified by comparing the simulation results and field measurements. Then using the validated numerical model, the horizontal deformation and vertical deformation of the roadway are systematically investigated and discussed. The results show that the rheological deformation of horizontal sidewall accounts for almost $30 \%$ of the whole deformation, and the stable time for such roadway is around 60 days after excavation. The tendency of the roof deformation is similar to the sidewalls, and however, the floor deformation is different because the roof exhibited rheological properties, while the floor normally displayed a plastic failure. The rheology of soft coal is critical for roadway stability, and then some suggestions for controlling the rheological roadway were proposed such as grouting, jet grouting, and delayed grouting and grouting rock bolts.

\section{Data Availability}

The Microsoft Excel Worksheet data used to support the findings of this study are available from the corresponding author upon request.

\section{Conflicts of Interest}

The authors declare that they have no conflicts of interest.

\section{Acknowledgments}

The work was supported by the projects of the Fundamental Research Funds for the Central Universities (2020ZDPY0221). The authors are grateful to Huaibei Mining (Group) Co. Ltd.

\section{References}

[1] R. Ma, G. Li, N. Zhang, C. Liu, Y. Wei, and M. Zhang, "Analysis on mechanism and key factors of surrounding rock instability in deeply inclined roadway affected by argillation and water seepage," International Journal of Mining Science and Technology, vol. 25, no. 3, pp. 465-471, 2015.

[2] G. Li, Z. Jiang, C. Lv, C. Huang, G. Chen, and M. Li, "Instability mechanism and control technology of soft rock roadway affected by mining and high confined water," International Journal of Mining Science and Technology, vol. 25, no. 4 , pp. 573-580, 2015.

[3] H. Xie, M. Gao, R. Zhang, G. Peng, W. Wang, and A. Li, "Study on the mechanical properties and mechanical response of coal mining at $1000 \mathrm{~m}$ or deeper," Rock Mechanics and Rock Engineering, vol. 52, no. 5, pp. 1475-1490, 2019.

[4] M.-C. He, H.-P. Xie, S.-P. Peng, and Y.-D. Jiang, "Study on rock mechanics in deep mining engineering," Yanshilixue $Y u$ Gongcheng Xuebao/Chinese J Rock Mech Eng, vol. 24, no. 16, pp. 2803-2813, 2005, https://www.engineeringvillage.com/ share/document.url?mid=cpx_18a992f1064ad5d09aM569120 $61377553 \&$ database $=$ cpx.

[5] X. Feng, N. Zhang, F. Xue, and Z. Xie, "Practices, experience, and lessons learned based on field observations of support failures in some Chinese coal mines," International Journal of
Rock Mechanics and Mining Sciences, vol. 123, Article ID 104097, 2019.

[6] G. Li, M. He, G. Zhang, and Z. Tao, "Deformation mechanism and excavation process of large span intersection within deep soft rock roadway," Mining Science and Technology (China), vol. 20, no. 1, pp. 28-34, 2010.

[7] Y. Sun, G. Li, J. Zhang, and J. Xu, "Failure mechanisms of rheological coal roadway," Sustainability, vol. 12, no. 7, p. 2885, 2020.

[8] Y. Sun, G. Li, J. Zhang, and D. Qian, "Experimental and numerical investigation on a novel support system for controlling roadway deformation in underground coal mines," Energy Science \& Engineering, vol. 8, no. 2, pp. 490-500, 2020.

[9] Y. Sun, G. Li, J. Zhang, and D. Qian, "Stability control for the rheological roadway by a novel high-efficiency jet grouting technique in deep underground coal mines," Sustainability, vol. 11, no. 22, Article ID 6494, 2019.

[10] Y. Sun, G. Li, and J. Zhang, "Investigation on jet grouting support strategy for controlling time-dependent deformation in the roadway," Energy Science \& Engineering, vol. 8, no. 6, pp. 2151-2158, 2020.

[11] H. Basarir, I. Ferid Oge, and O. Aydin, "Prediction of the stresses around main and tail gates during top coal caving by 3D numerical analysis," International Journal of Rock Mechanics and Mining Sciences, vol. 76, pp. 88-97, 2015.

[12] P. H. S. W. Kulatilake, Q. Wu, Z. Yu, and F. Jiang, "Investigation of stability of a tunnel in a deep coal mine in China," International Journal of Mining Science and Technology, vol. 23, no. 4, pp. 579-589, 2013.

[13] Q.-S. Bai, S.-H. Tu, F.-T. Wang, X.-G. Zhang, H.-S. Tu, and Y. Yuan, "Observation and numerical analysis of the scope of fractured zones around gateroads under longwall influence," Rock Mechanics and Rock Engineering, vol. 47, no. 5, pp. 1939-1950, 2014.

[14] Q. Wang, B. Jiang, R. Pan et al., "Failure mechanism of surrounding rock with high stress and confined concrete support system," International Journal of Rock Mechanics and Mining Sciences, vol. 102, pp. 89-100, 2018.

[15] H. Basarir, Y. Sun, and G. Li, "Gateway stability analysis by global-local modeling approach," International Journal of Rock Mechanics and Mining Sciences, vol. 113, pp. 31-40, 2019.

[16] W. Yu, B. Pan, F. Zhang, S. Yao, and F. Liu, "Deformation characteristics and determination of optimum supporting time of alteration rock mass in deep mine," KSCE Journal of Civil Engineering, vol. 23, no. 11, pp. 4921-4932, 2019.

[17] E. Hoek, P. G. Marinos, and V. P. Marinos, "Characterisation and engineering properties of tectonically undisturbed but lithologically varied sedimentary rock masses," International Journal of Rock Mechanics and Mining Sciences, vol. 42, no. 2, pp. 277-285, 2005.

[18] E. Hoek, C. Carranza-Torres, and B. Corkum, "Hoek-Brown failure criterion-2002 edition," Proc NARMS-Tac, vol. 1, no. 1, pp. 267-273, 2002.

[19] E. Hoek and M. S. Diederichs, "Empirical estimation of rock mass modulus," International Journal of Rock Mechanics and Mining Sciences, vol. 43, no. 2, pp. 203-215, 2006.

[20] Z. Guan, Y. Jiang, Y. Tanabashi, and H. Huang, "A new rheological model and its application in mountain tunnelling," Tunnelling and Underground Space Technology, vol. 23, no. 3, pp. 292-299, 2008.

[21] Z. Guan, Y. Jiang, and Y. Tanabashi, "Rheological parameter estimation for the prediction of long-term deformations in conventional tunnelling," Tunnelling and Underground Space Technology, vol. 24, no. 3, pp. 250-259, 2009. 
[22] F. Yang, C. Zhang, H. Zhou et al., "The long-term safety of a deeply buried soft rock tunnel lining under inside-to-outside seepage conditions," Tunnelling and Underground Space Technology, vol. 67, pp. 132-146, 2017.

[23] M. Sharifzadeh, A. Tarifard, and M. A. Moridi, "Time-dependent behavior of tunnel lining in weak rock mass based on displacement back analysis method," Tunnelling and Underground Space Technology, vol. 38, pp. 348-356, 2013.

[24] A. Sainoki, S. Tabata, H. S. Mitri, D. Fukuda, and J.-I. Kodama, "Time-dependent tunnel deformations in homogeneous and heterogeneous weak rock formations," Computers and Geotechnics, vol. 92, pp. 186-200, 2017.

[25] Y. Kang, Q. Liu, H. Xi, and G. Gong, "Improved compound support system for coal mine tunnels in densely faulted zones: a case study of China's Huainan coal field," Engineering Geology, vol. 240, pp. 10-20, 2018.

[26] Y. Kang, Q. Liu, G. Gong, and H. Wang, “Application of a combined support system to the weak floor reinforcement in deep underground coal mine," International Journal of Rock Mechanics and Mining Sciences, vol. 71, pp. 143-150, 2014.

[27] Y.-Y. Jiao, L. Song, X.-Z. Wang, and A. Coffi Adoko, "Improvement of the $\mathrm{U}$-shaped steel sets for supporting the roadways in loose thick coal seam," International Journal of Rock Mechanics and Mining Sciences, vol. 60, pp. 19-25, 2013.

[28] M. H. Salimian, A. Baghbanan, H. Hashemolhosseini, M. Dehghanipoodeh, and S. Norouzi, "Effect of grouting on shear behavior of rock joint," International Journal of Rock Mechanics and Mining Sciences, vol. 98, pp. 159-166, 2017.

[29] Y. Sun, J. Zhang, G. Li, Y. Wang, J. Sun, and C. Jiang, "Optimized neural network using beetle antennae search for predicting the unconfined compressive strength of jet grouting coalcretes," International Journal for Numerical and Analytical Methods in Geomechanics, vol. 43, no. 4, pp. 801813, 2019.

[30] Y. Sun, G. Li, N. Zhang, Q. Chang, J. Xu, and J. Zhang, "Development of ensemble learning models to evaluate the strength of coal-grout materials," International Journal of Mining Science and Technology, vol. 31, no. 2, pp. 153-162, 2020.

[31] Y. Sun, G. Li, H. Basarir, A. Karrech, and M. R. Azadi, "Laboratory evaluation of shear strength properties for cement-based grouted coal mass," Arabian Journal of Geosciences, vol. 12, no. 22, 2019. 